$\underline{\text { Short Communication }}$

\title{
ANALYSIS ON CHANGING REGULATION OF BODY WEIGHT AND EGG WEIGHT OF CHINESE INDIGENOUS GOOSE (SHITOU GOOSE) IN OFF-SEASON BREEDING
}

\author{
Y. Guo ${ }^{1}$, Z. H. Zhao ${ }^{1}$, Q. Ni ${ }^{1}$, X. Q. Chen ${ }^{1}$, L. X. Li ${ }^{3,4}$, B. Balasubramanian ${ }^{2}$, R. M. Jia ${ }^{1 *}$ and W. C. Liu $^{1 *}$ \\ ${ }^{1}$ Department of Animal Science, College of Coastal Agricultural Sciences, Guangdong Ocean University, Zhanjiang, \\ Guangdong 524088, P. R. China \\ ${ }^{2}$ Department of Food Science and Biotechnology, College of Life Science, Sejong University, Seoul 05006, South Korea \\ ${ }^{3}$ Guangdong Lixing Agricultural Development Co., Ltd., Guangdong 515729, P. R. China \\ ${ }^{4}$ Raoping Fubin Shitou goose original breeding base Co., Ltd., Guangdong 515732, P. R. China \\ *Correspondence: jiarm@gdou.edu.cn; liuwc@gdou.edu.cn
}

\begin{abstract}
The present experiment was conducted to investigate the changes of body weight and egg weight in Shitou geese during off-season breeding period, and compared with the productive data of Hy-line layers. A total of 364 male geese and 2000 female geese aged 2 years old were forced to molt. The changes of body weight, egg production and egg weight of the geese were recorded from the moratorium in February to the end of December. It was found that the body weight of female geese was significantly different in April and June $(\mathrm{P}<0.05)$, but decreased slowly in the late period and the difference was not significant $(\mathrm{P}>0.05)$. The body weight of male geese fluctuated, and there was no linear downward trend. Otherwise, the egg weight increased significantly from April to June, and then decreased slowly, showing wavy changes. Meanwhile, there was a significant positive correlation between female geese body weight and egg weight during breeding period $(r=0.584)$. In addition, the change rule of body weight and egg weight of Shitou goose is opposite to that of chicken.
\end{abstract}

Keywords: Shitou geese; body weight; egg weight; off-season breeding

https://doi.org/10.36899/JAPS.2021.3.0282

Published online November 20, 2020

\section{INTRODUCTION}

Shitou goose is one of the largest meat geese breeds in the world. It has the characteristics of large body, strong roughage tolerance, fast growth rate, strong stress resistance, low feed consumption and good meat quality (Lin et al., 2019). On the other hand, the Shitou goose is easy to raise, high efficiency, simple production facilities and low feeding cost, so it is suitable for farmers to raise (Liu et al., 2014). Geese have obvious breeding and production seasonality. Normal breeding geese enter the breeding and laying period in September every year, stop laying eggs at the end of May of the following year, enter the closed period, and do not lay eggs in the hot season from June to August (Shi et al., 2008). This obvious seasonal reproduction has greatly reduced the supply of meat geese in autumn and winter (Chen, 2014). It also leads to great fluctuations in the price of goose seedlings in summer and winter. With the progress of production technology, a large number of breakthroughs have been made in the research of off-season breeding technology of geese, and production technology and practical experience have been popularized. The goose industry in China is developing rapidly, the scale of breeding is getting larger and larger, and it is gradually developing in the direction of scale and industrialization (Shi and Sun, 2011). However, the reproductive performance of Shitou goose has always been at a low level, with low egg production and low quality of goose seedlings, which have seriously restricted the healthy development of Shitou goose industrialization and are the problems faced by breeding enterprises at present. Nevertheless, the reproductive performance of Shitou goose has always been at a low level, with low egg production and low quality of goose seedlings, which have seriously restricted the healthy development of Shitou goose industrialization and are the problems faced by breeding enterprises at present.

Body weight and egg weight are important characteristics of poultry breeds (Yang, 2002). A study carried by Lacin, et al., (2008) demonstrated that the body weight of the first laying chicken directly affected the egg weight and egg production, and there was a positive correlation between egg weight and birth weight. The lighter weight hens have late sexual maturity, lay fewer eggs in the early period, and have a high mortality rate. As far as breeding enterprises are concerned, within a certain range, cultivating the uniformity of the chicken flocks and appropriately increasing the average weight of the flocks are of great help to increase the economic benefits (Dai, 2004). As a large-scale breed at present, the laying performance of Shitou goose has been at a low level. At present, due to the lack of theoretical guidance and the excessive pursuit of economic benefits, the 
production performance of Shitou goose has not been significantly improved. Previous studies on Shitou geese generally focused on fertilization rate, hatching rate (Duan, et al., 2006), growth performance (Tang, et al., 2011) and so on. However, few studies focused on the changes of body weight and egg weight. It is still unknown whether the changing law of chickens can be applied to Shitou geese. Therefore, in this experiment, the body weight and egg weight of Shitou geese in the whole off-season breeding period were measured systematically, and then compared with the reproductive performance of Hy-line laying hens to explore the change law and physiological mechanism of body weight and egg weight of geese during off-season breeding, so as to provide reference for the breeding and off-season production of Shitou goose.

\section{MATERIALS AND METHODS}

Birds, Diets and Experimental Procedures: In total, 2,000 female and 364 male healthy geese with the age of two-years-old were obtained from Guangdong Lixing Agricultural Development Co., Ltd. The mating ratio of male and female geese was 1:5.5, and all the geese mate naturally in the water. The experimental period was from April to December. All the geese were raised in a farm with goose houses, land sports grounds and water baths. The geese house adopted shed feeding, flat breeding and semi-open breeding house. The two walls of the goose house were equipped with fans to keep the goose house ventilated and keep the water clean. Spray water on the land sports ground and trees to cool down regularly every afternoon to prevent the high temperature in summer from causing fire and reduce the high temperature heat stress response of geese in summer. Normal immunization procedures were used during reproduction. The laying period was mainly fed with full-price compound feed provided by Guangdong Lixing Agricultural Development Co., Ltd., supplemented by an appropriate amount of green water plants, and added the right amount of $\mathrm{VE}$ and glucose when the weather was hot. Fed regularly and quantitatively, and the geese had free access to food and water. The sunshine time of geese during the non-parturition period was controlled at 18 hours per day. After stopping production, the molting was carried out manually and the light time was adjusted. It was necessary to deal with the nesting phenomenon of geese in time and replenish nutrition.

Sampling and Measurements: During the experiment, collect all the eggs and keep the eggshells clean. The storage temperature of the egg breeding bank was between 10 and $20{ }^{\circ} \mathrm{C}$. The breeding eggs were hatched once a week. The determination of productive parameters based on our previous studies (Liu et al., 2019; Liu et al., 2020; Guo et al., 2020a; Guo et al., 2020b). Before hatching, 35 breeding eggs were randomly selected from the egg bank to be weighed and recorded. Every 2 months, 50 male and 50 female Shitou geese were randomly selected and weighed and recorded. The average body weight $(\mathrm{kg})$, average egg weight $(\mathrm{g})$, egg production and the correlation coefficient between goose weight and egg weight in each period were calculated.

Statistical Analysis: All data were compared by single factor analysis of variance with SPSS19.0 software. The monthly body weight of Shitou geese was compared by LSD method, and the correlation between body weight, egg production and egg weight were tested. $\mathrm{P}<0.05$ was considered to be statistically significant.

\section{RESULTS AND DISCUSSION}

The average body weight of Shitou geese during the breeding period were described in Table 1. In February and June, the body weight of male and female geese were significantly different from that of other months $(\mathrm{P}<0.05)$. The body weight of male geese decreased significantly in April and October $(\mathrm{P}<0.05)$, which showed that the body weight fluctuated greatly during the whole breeding period. The body weight of female geese changed significantly in April and June $(\mathrm{P}<$ $0.05)$, which showed that the body weight of female geese changed greatly before the beginning of parturition. On the other hand, the body weight of female geese decreased slowly from June to December and the difference was not significant $(\mathrm{P}>0.05)$.

Table 1. Analysis of body weight of Shitou geese.

\begin{tabular}{lcc}
\hline \multirow{2}{*}{ Month } & \multicolumn{2}{c}{ Body weight } \\
\cline { 2 - 3 } & Male geese & Female geese \\
\hline 2 & $8.78 \pm 1.01^{\mathrm{a}}$ & $5.60 \pm 0.68^{\mathrm{b}}$ \\
6 & $7.90 \pm 0.81$ & $6.91 \pm 0.58$ \\
8 & $8.41 \pm 0.72^{\mathrm{b}}$ & $7.44 \pm 1.02^{\mathrm{a}}$ \\
10 & $8.10 \pm 0.59$ & $6.98 \pm 0.67$ \\
12 & $7.75 \pm 0.96$ & $6.69 \pm 0.75$ \\
\hline
\end{tabular}


Different letters of shoulder marks in the same column indicate significant difference $(\mathrm{P}<0.05)$. The same letter indicates that the difference is not significant $(\mathrm{P}>0.05)$.

As shown in table 2, there was a significant positive correlation between female goose body weight and egg weight ( $\mathrm{P}<0.05)$. As shown in Fig. 1, the body weight and egg production of Shitou geese showed a downward trend from June to October. As can be seen from Fig. 2, the body weight and egg weight of female geese decreased from April to December, and the egg weight showed a wavy decline. Although both body weight and egg weight increased in the early period of egg laying (from April to June), they began to decrease slowly in June. After October, this downward trend is obvious.

Table 2. Correlation between body weight and egg weight of Hy-line white laying hens and Shitou geese.

\begin{tabular}{l}
\hline \multicolumn{1}{c}{ Female geese weight } \\
$\begin{array}{l}\mathrm{r}=0.584^{*} \\
\text { Egg weight }\end{array}$ \\
$\begin{array}{l}\text { The belt } * \text { indicates that the correlation is significant }(\mathrm{P}<0.05), \text { and the belt } * \text { indicates that the correlation is extremely } \\
\text { significant }(\mathrm{P}<0.01) .\end{array}$ \\
\hline
\end{tabular}

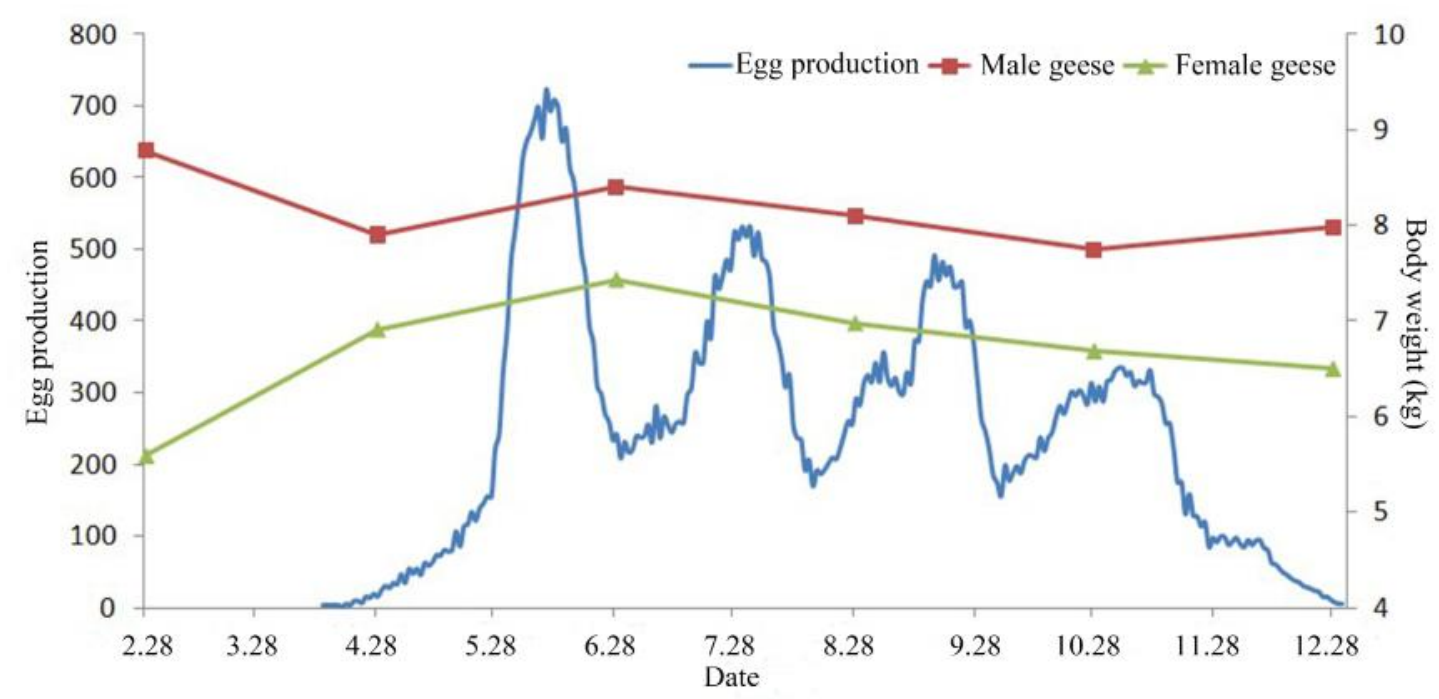

Fig. 1 Changes of body weight and egg production in off-season breeding period of Shitou geese

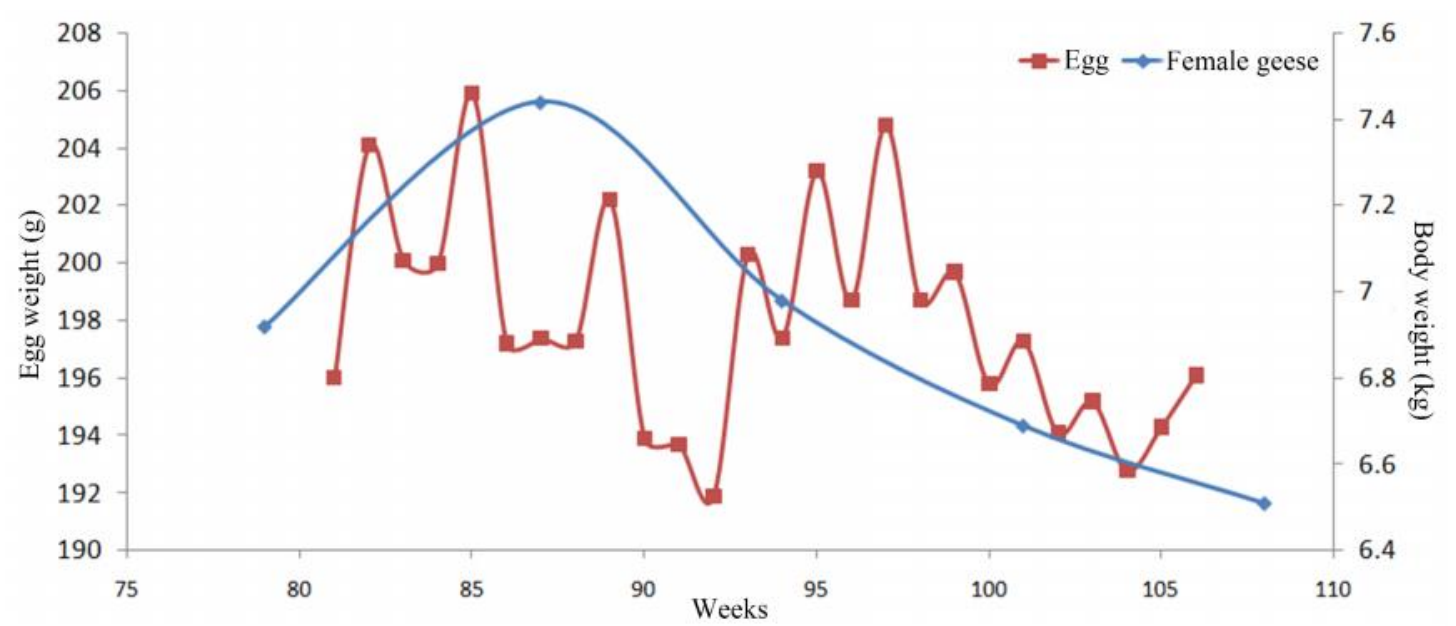

Fig. 2 Changes of body weight and egg weight in off-season breeding season of female goose

The study of Han and Zhao (2008) shows that there was a certain relationship between female goose weight and egg weight, mainly because the body weight of female geese affected the length of vertical and horizontal diameter of eggs. It was consistent with the results of this experiment. The geese in the period of stopping 
production and molting consumed less energy and only needed to maintain the energy of daily activities. When the feed intake is constant, the daily energy intake is more than the energy needed to maintain the daily activities of the body, so part of the nutrition is converted into muscle and fat, resulting in female goose weight gain (Shi et al., 2008). When a certain number of eggs were laid, nesting behavior occurred in the geese (Jia et al., 2011). With the reduction of daily behavior activities of female geese during the nest period, including feeding and egg laying behavior, the energy intake was lower than the energy consumed, resulting in weight loss and affecting the egg laying peak period of the whole goose flock (Huang et al., 2008). After laying, the body load of female geese increased, the physique was affected, and some geese showed pathological changes, which affected feeding, digestion and absorption, and affected body weight and egg laying performance. In addition, there were also many factors that affected the body weight of geese during the breeding period, such as excessive temperature caused a series of physiological adverse reactions (Huang and Shi, 2008) and the decline of water quality in the late period of reproduction had a direct impact on the health of geese (Huang et al., 2010).

Since Hy-line laying hens are specialized laying hens, there are many studies on the relationship between laying and off-season breeding, so this experiment was compared with Hy-line laying hens. In the study of Hyline laying hens by Terborgh and Duke University (2006), the body weight and egg weight of molted laying hens increased rapidly at the beginning of laying, and then began to stabilize, compared with those before forced molting, and there was a highly significant positive correlation between hen weight and egg weight $(\mathrm{P}<0.01)$. This was contrary to the change law of geese in this experiment. The hens weight increased with the extension of the laying time, the growth rate was obvious in the early period (from April to June), and slows down from August to December, and the egg weight also reflected this rule. It could be seen that the laying mechanisms of the two were very different. At present, the change mechanism of egg weight of goose could not draw other conclusions, whether to increase the weight of female geese to change the law of egg weight, needs to be further explored. This experiment only analyzed the body weight and egg weight of Shitou geese in four laying periods during off-season breeding. There were many factors affecting the body weight and egg weight of Shitou geese, such as disease, water quality and so on (Guo et al., 2012), which could not be taken into account. Hence, the research on the law of body weight and egg weight of Shitou goose needs continuous discussion and practical analysis, so that the breeding law of Shitou goose can be studied and analyzed more systematically and scientifically.
Conclusion: In summary, the body weight and egg weight of Shitou goose showed an overall downward trend during the off-season breeding, and there was a significant positive correlation between egg weight and body weight of female geese. This characteristic was opposite to that of chicken. The mechanism of egg weight of lion-headed goose needs to be further studied.

Authors' Contribution: RM Jia conceived and designed the study, $\mathrm{ZH}$ Zhao and B Balasubramanian helped in preparation of the manuscript, Q Ni, XQ Chen, and LX $\mathrm{Li}$ performed experimental work, Y Guo and WC Liu analyzed the data and wrote the article, WC Liu and $\mathrm{ZH}$ Zhao revised the manuscript.

Acknowledgments: This research was funded by Innovation team of modern agricultural industrial technology system in Guangdong Province (2019KJ137); Chaozhou science and technology plan project (2017N05); Variety selection and healthy breeding of Shitou goose (B15337); Raoping County Science and technology plan project (RAOJIN [2018] No. 43).

Conflicts of Interest: The authors declare they have no conflict of interest.

\section{REFERENCES}

Chen, J. (2014). Exploration on laying techniques of breeding Geese in Summer. ShuiQin ShiJie. $4: 14-15$.

Dai, Y.G. (2004). Feeding techniques in the early growth period of broilers. Contemp. Livest. Poult. Breed. Indus. 5:3-4.

Duan, X.J., D.Q. Gong, H.T. Wei and L.H. Wang (2006). Comparison of Reproductive performance of different Goose breeds. Chin. J. Anim. Husb. 42(17):17-19.

Guo, J.B., M.Q. Hu and J.H. Zhang (2012). Effects of hybridization facility of flowing water ditch on the reproductive performance of Magang goose. J. Anhui Agri. Sci. 31:213-214.

Guo, Y., Z.H. Zhao, Z.Y. Pan, L.L. An, B. Balasubramanian, and W.C. Liu (2020a). New insights into the role of dietary marine-derived polysaccharides on productive performance, egg quality, antioxidant capacity, and jejunal morphology in late-phase laying hens. Poult. Sci. 99:2100-2107.

Guo, Y., B. Balasubramanian, Z.H. Zhao, and W.C. Liu (2020b). Marine algal polysaccharides alleviate aflatoxin B1-induced bursa of Fabricius injury by regulating redox and apoptotic signaling pathway in broilers. Poult. Sci. https://doi.org/10.1016/j.psj.2020.10.050. 
Han, ZB and J.Y. Zhao (2008). Analysis of physical Properties of Gushi Goose Egg. J. Anhui Agri. Sci. 4:29-36.

Huang, Y.M., Z.D. Shi, Z. Liu, Y. Liu and X.W. Li (2008). Endocrine regulations of reproductive seasonality, follicular development and incubation in Magang Geese. Anim. Reprod. Sci. 4:344-358.

Huang, Y.M. and Z.D. Shi (2008). Measures to improve the off-season production level of Guangdong grey geese. Chin. Poult. 30(5):46-48.

Huang, Y.M., Y. Zhang, Z.D. Shi and Y.B. Tian (2010). Effect of water quality of goose farm bathing pool on production performance of breeder geese. Chin. Poult. 33(22):62-64.

Jia, R.M., H.Y. Wu, Y. Liu, and L. Zhang (2011). Cloning and prokaryotic expression of PRL gene in Shitou goose. Acta Veterinaria et Zootechnica Sinica. 42(3):343-348.

Lacin, E., A. Yildiz, N. Esenbuga and M. Macit (2008). Effects of differences in the initial body weight of groups on laying performance and egg quality parameters of Lohmann laying hens. Czech J. Anim. Sci. 11:466-471.

Lin, S.X., Y.X. Pan, L. Huang, X. Li and Y.W. Zhu (2019). Breeding and management of Shitou goose. Guangdong Anim. Husband. Vet. Sci. Technol. 5:26-27.

Liu, W., Y. Yuan, C. Sun, B. Balasubramanian, Z. Zhao, and L. An (2019). Effects of dietary betaine on growth performance, digestive function, carcass traits, and meat quality in indigenous yellow- feathered broilers under long-term heat stress. Animals 9(8):506.

Liu, W.C, Y. Guo, Z.H. Zhao, R. Jha and B. Balasubramanian (2020). Algae-derived polysaccharides promote growth performance by improving antioxidant capacity and intestinal barrier function in broiler chickens. Front. Vet. Sci. 7:601336.

Liu, Y.S., L.J. Yin and B. Ju (2014). The main points of breeding techniques of Shitou goose. ShuiQin ShiJie. 5:8-9.

Meltofte H. (2006). Populations and breeding performance of divers, geese and ducks at Zackenberg, northeast Greenland, 1995-2005. Wildfowl. 56:129-151.

Shi, Z.D., Y.M. Huang and W. Wu (2008). Review of studies on egg laying cycle and its physiological regulation mechanism in geese. Chin. Poult. 30(9):1-5.

Shi, Z.D. and A.D. Sun (2011). Regulation and matching techniques of Goose breeding season. Chin. Poult. 33(18):40-42.

Tang, X.G., X.Y. Peng, J.Y. Sun and G.W. Wei (2011). General situation of Research on production performance of Shitou goose. Guangdong J. Anim. Vet. Sci. 36(4):3-4.

Terborgh, J. and Duke University (2006). Genetic Excellence of the Hy-Line Variety W-98. Commercial Management Guide. 6:8-21.

Yang, N. (2002). Poultry production science. Chin. Agri. Press. 120-128. 